\title{
CORROSÃO DE AÇO CARBONO PARA DUTOS EM ÁGUAS NATURAIS
}

\author{
S. R. PETERS ${ }^{1}$, L. R. M. LIMA ${ }^{1}$, S. N. SILVA² e L. M. RODRIGUES ${ }^{1}$ \\ ${ }^{1}$ Universidade Federal do Pampa, Campus Bagé, Engenharia Química \\ ${ }^{2}$ Universidade Federal do Pampa, Campus Bagé, Engenharia de Energias Renováveis e \\ Ambiente \\ E-mail para contato: luciana.rodrigues@unipampa.edu.br
}

\begin{abstract}
RESUMO - Este trabalho objetiva investigar o caráter corrosivo de águas naturais sobre amostras metálicas de aço carbono, comumente empregado na construção de dutos para o transporte de petróleo e derivados. Foram avaliadas água do mar (coletada no município de Rio Grande-RS) e água de rio (coletada no rio Quebracho no município de Bagé-RS). O metal utilizado na pesquisa foi aço carbono tipo API 5L Grau B. O estudo baseou-se na caracterização físico-química das amostras de águas naturais, preparação e análise morfológica das amostras metálicas, estudo da corrosão das amostras metálicas expostas aos respectivos meios, caracterização microscópica do ataque corrosivo e cálculo da taxa de corrosão, segundo norma ASTM G1-90. O tipo do ataque ao metal foi avaliado a diferentes tempos de exposição às águas naturais, variando de $10 \mathrm{~min}$ a $120 \mathrm{~h}$. Ambos os tipos de águas mostraram-se como meios corrosivos ao metal, mas a taxa de corrosão do aço submetido à água do mar foi cerca de 5 vezes maior do que em água de rio. Para menores tempos de exposição (até 60min) o ataque ao metal foi do tipo localizado, e para maiores tempos (até 120h), o ataque foi generalizado. Ressalta-se a importância de se proteger adequadamente estruturas metálicas expostas aos ambientes de água salgada e doce.
\end{abstract}

\section{INTRODUÇÃO}

A corrosão é a deterioração de material, geralmente metálico, por ação química ou eletroquímica do meio ambiente, associada ou não a esforços mecânicos (GENTIL, 2008). A Corrosão assume grande importância na vida moderna, pois é um processo espontâneo e está constantemente transformando os materiais, diminuindo e limitando sua durabilidade e desempenho (GEMELI, 2001).

Os principais meios corrosivos são (UHLIG, 1963) a atmosfera (urbana, rural, industrial, marítima, etc); águas naturais (água potável, água do mar, água doce, água para indústria, etc); solo; produtos químicos; alimentos; madeira; e plásticos.

Deve-se destacar a importância que representa a natureza do meio corrosivo que se encontra na imediata proximidade da superfície metálica. Os materiais metálicos em contato com a água tendem a sofrer corrosão, a qual vai depender de várias substâncias que podem estar contaminando a mesma (FURTADO, 1981; GENTIL, 2008). Contaminantes mais frequentes são gases dissolvidos $\left(\mathrm{O}_{2}, \mathrm{~N}_{2}, \mathrm{CO}_{2}, \mathrm{Cl}_{2}, \mathrm{SO}_{2}, \mathrm{SO}_{3}, \mathrm{H}_{2} \mathrm{~S}, \ldots\right)$, sais dissolvidos 
(cloreto de sódio, de ferro e de magnésio, carbonato de sódio, bicarbonato de cálcio...), matéria orgânica de origem animal ou vegetal, bactérias, limos, algas, sólidos suspensos, etc. Também deve ser considerado o $\mathrm{pH}$, a temperatura e a velocidade de agitação da água.

Os sais podem agir acelerando ou retardando a velocidade do processo corrosivo. Entre os sais que influenciam com maior frequência a corrosão estão: cloretos, sulfatos, sais, bicarbonatos de cálcio, magnésio e de ferro. O efeito do cloreto de sódio, na corrosão, deve-se ao fato de este sal ser um eletrólito forte, ocasionando, portanto, aumento de condutividade, que é fundamental no mecanismo eletroquímico. $\mathrm{O}$ íon cloreto atua também na despassivação do aço inox e das ligas de alumínio, visto que ele pode penetrar na camada protetora de óxido de $\mathrm{Cr}$ e de $\mathrm{Al}$.

No caso de presença de íons sulfato, $\mathrm{SO}_{4}{ }^{2-}$, deve-se considerar a possibilidade de ocorrência de corrosão microbiológica, originada por bactérias redutoras de sulfato, acelerando o processo corrosivo.

Entre os gases mais comumente encontrados na água pode-se destacar: $\mathrm{O}_{2}, \mathrm{H}_{2} \mathrm{~S}, \mathrm{SO}_{2}$, $\mathrm{SO}_{3}, \mathrm{NH}_{3}, \mathrm{CO}_{2}$ e $\mathrm{Cl}_{2}$. Alguns desses gases são encontrados sempre na água, como o $\mathrm{O}_{2}$ e o $\mathrm{CO}_{2}$, enquanto outros ocorrem na água provenientes da absorção de poluentes atmosféricos ou devido ao tratamento com o cloro.

Geralmente a água contém diversas partículas em suspensão, as quais necessitam ser removidas a fim de tornar a água adequada ao uso. Estas partículas atuam na corrosão da seguinte forma (PANOSSIAN, 1993): podem ser absorvidas pela torre de resfriamento e também podem ser poluentes atmosféricos sólidos; podem se depositar em tubos trocadores de calor, reduzindo a eficiência térmica do equipamento e causando a corrosão sob o depósito; podem causar a dureza da água e mudanças no $\mathrm{pH}$; e podem acelerar o processo de erosão.

A presença de matéria orgânica na água pode resultar no crescimento biológico, o qual pode causar nas águas industriais o crescimento de algas, fungos e bactérias; a formação de meio ácido; a despolarização da área catódica por bactéria redutora de sulfato; e a formação de tubérculos de óxidos de ferro hidratados.

A ação corrosiva da água do mar pode ser determinada inicialmente por sua salinidade. Essa salinidade é praticamente constante em oceanos, mas pode variar em mares. A água do mar é um meio corrosivo complexo (LAQUE, 1975) constituído de sais, matéria orgânica viva, matéria orgânica em decomposição e gases dissolvidos. Logo, a ação corrosiva da água do mar não se restringe à ação isolada da salinidade, ocorrendo uma ação conjunta dos diferentes constituintes.

Ao submergir estruturas metálicas em água do mar, inicia-se um processo de incrustação proveniente de organismos vegetais ou animais, que crescem aderentes à superfície metálica. Há proliferação de algas, limos, mexilhões, que poderão formar um depósito extremamente duro e aderente, o biofouling (LAQUE, 1975).

\section{EXPERIMENTAL}


As amostras de águas naturais foram coletadas no mar, costa litorânea de Rio GrandeRS, oceano Atlântico, e no rio, em Bagé-RS, no rio Quebracho. As amostras foram coletadas de maneira adequada a evitar-se contaminação, sendo imediatamente encaminhadas para análise em laboratório.

As amostras metálicas de aço carbono tipo API 5L Grau B foram cedidas por empresa responsável pela distribuição de petróleo e derivados no estado do RS. Os equipamentos utilizados na execução da pesquisa foram: medidor de $\mathrm{pH}$ digital, condutivímetro digital, medidor de oxigênio dissolvido, turbidímetro, microscópio óptico biológico e estereomicroscópio e balança analítica.

As amostras de águas naturais foram caracterizadas quanto ao valor de $\mathrm{pH}$, índice de turbidez, oxigênio dissolvido e condutividade elétrica. As amostras metálicas foram preparadas por corte, polimento em lixas d'água até \#2000, sendo sua morfologia caracterizada por microscopia óptica.

O estudo da corrosão foi procedido com a exposição das amostras metálicas preparadas nas respectivas amostras de águas de 10min a 120h de exposição. As amostras metálicas foram continuamente monitoradas quanto a sua variação de massa e morfologia do ataque. Por fim, a taxa de corrosão do aço API foi determinada segundo a norma ASTM G1-90, para cada um dos meios agressivos.

\section{RESULTADOS}

As amostras de águas naturais foram caracterizadas fisico-quimicamente e os resultados são apresentados na Tabela 1.

Tabela 1 - Caracterização das amostras de águas naturais.

\begin{tabular}{|l|c|c|}
\hline \multicolumn{1}{|c|}{ Parâmetros físico-químicos } & \multicolumn{2}{c|}{ Amostras de águas } \\
\cline { 2 - 3 } & mar & rio \\
\hline $\mathrm{pH}$ & 7,72 & 7,50 \\
\hline Condutividade elétrica $\left(\mathrm{mS} / \mathrm{cm}^{2}\right)$ & 45,0 & 0,30 \\
\hline Índice de turbidez (NTU) & 53,00 & 7,76 \\
\hline Teor de oxigênio dissolvido $(\mathrm{ppm})$ & 8,54 & 10,15 \\
\hline
\end{tabular}

A morfologia da amostra metálica de aço carbono API 5L Grau B preparada por lixamento, antes de qualquer exposição a meio agressivo, é apresentada na Figura 1. 
Figura 1 - Morfologia da amostra metálica antes de exposição, 200x de aumento.

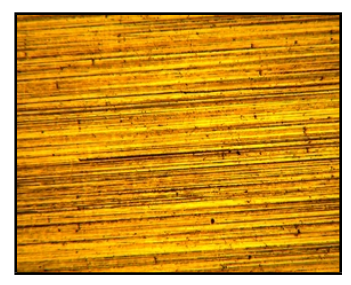

As amostras de aço carbono expostas durante $10 \mathrm{~min}$ à $120 \mathrm{~h}$ em água de rio e água do mar são apresentadas nas Figuras 2 a 5. Observa-se a rápida nucleação do ataque à superfície metálica, com a formação de pites (ataque localizado), já à 10min de exposição.

Figura 2 - Ataque em 10min de exposição à (a) água de rio e (b) água do mar, 40x de aumento.

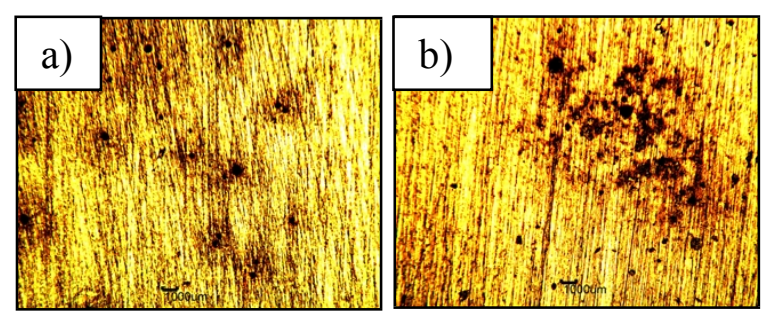

Figura 3 - Ataque em 40min de exposição à (a) água de rio e (b) água do mar, 40x de aumento.

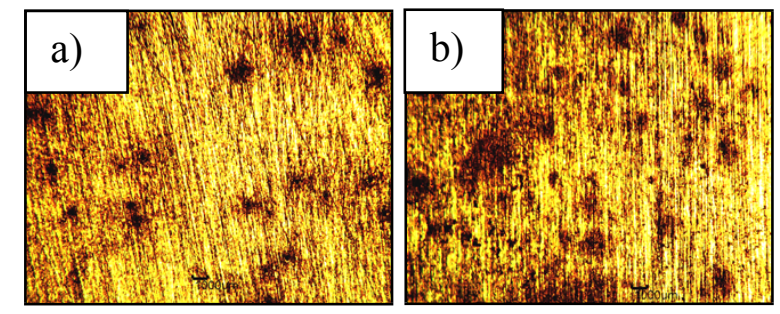

O ataque localizado se intensifica na primeira hora de exposição aos meios.

Figura 4 - Ataque em 24h de exposição à (a) água de rio e (b) água do mar, 40x de aumento.
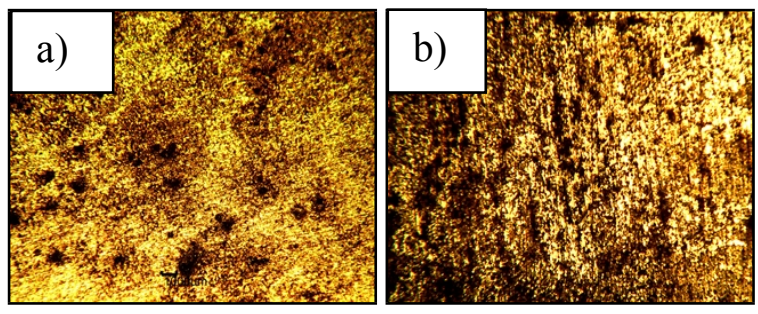

Em um período mais longo de exposição de 120h, o ataque progride ao tipo generalizado, abrangendo toda a superfície metálica. Nota-se que o ataque referente à água do 
mar é mais intenso do que em água de rio. Mas o meio de água doce também apresenta um nível de agressividade ao aço.

Figura 5 - Ataque em 120h de exposição à (a) água de rio e (b) água do mar, 40x de aumento.

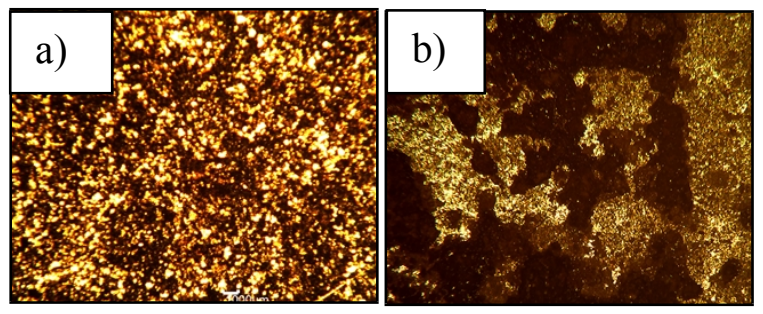

A taxa de corrosão das amostras metálicas determinada para o tempo máximo de exposição de $120 \mathrm{~h}$ foi de $0,56 \mathrm{~mm}$ /ano para exposição em água do mar, e de $0,12 \mathrm{~mm} /$ ano para exposição em água de rio.

Removendo-se os produtos de corrosão formados durante o ataque, observa-se nitidamente o ataque ao substrato metálico. Na Figura 6 nota-se o ataque localizado ao metal, com a formação de pite, em ambos os meios agressivos.

Figura 6 - Ataque localizado ao metal após remoção do produto de corrosão formado em 10min de exposição, a) água do mar e b) água de rio, 100x de aumento.

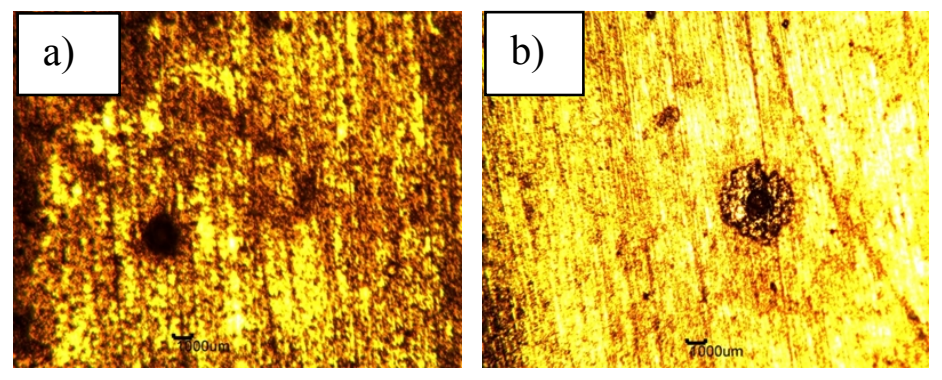

\section{CONCLUSÕES}

Este trabalho permitiu constatar a agressividade das águas naturais estudadas, de mar e rio. A água do mar mostrou-se mais agressiva ao aço API 5L Grau B. Para menores tempos de exposição (até $60 \mathrm{~min}$ ) ocorreu o ataque localizado ao aço API 5L Grau B, e para maiores tempos de exposição (até $120 \mathrm{~h}$ ) ocorreu o ataque generalizado ao aço.

A variação de massa foi pequena, considerando o tempo máximo de exposição $(120 \mathrm{~h})$. Nota-se o ataque à matriz metálica após a remoção de produtos de corrosão. A taxa de corrosão do aço API foi 4,7x maior em água do mar, do que em água de rio.

Ressalta-se a importância do emprego da adequada proteção de estruturas metálicas expostas a ambientes de águas naturais, tanto de mar como de rio. 


\section{REFERENCIAS}

GEMELLI, E. Corrosão de Materiais Metálicos e Sua Caracterização. LTC: Rio de Janeiro, 2001.

UHLIG, H. H. Corrosion and Corrosion Control. John Wiley \& Sons: NY, 1963.

FURTADO, P. Introdução à Corrosão e Proteção das Superficies. Imprensa Universitária, UFMG, 1981.

GENTIL, V. Corrosão. LTC: Rio de Janeiro, 2008.

LAQUE, F. L. Marine Corrosion. John Wiley \& Sons: NY, 1975.

NORMA TÉCNICA ASTM G1-90 (1999) Standard Practice for Preparing, Cleaning, and Evaluating Corrosion Test Specimens.

PANOSSIAN, Z. Corrosão e Proteção contra Corrosão em Equipamentos e Estruturas Metálicas. 1ed. IPT - Instituto de Pesquisas Tecnológicas: São Paulo, 1993. v. 2, 356p. 